\title{
O Design de Interação: Uma Abordagem para Jogos Educativos Centrados no Usuário
}

\author{
Interaction design: approach for user-centered educational games \\ Anelise Thaler \\ Universidade Federal de Santa Catarina, UFSC \\ - Brasil \\ anethaler@gmail.com \\ - Francisco Antônio Pereira Fialho \\ Universidade Federal de Santa Catarina, UFSC \\ - Brasil \\ fapfialho@gmail.com
}

\begin{abstract}
Design current fetching constantly for products that satisfy the necessities increasing of the human being, conceives new products looking for to take care of the expectations of the users, of satisfactory, constant form that it is possible to connect in any place. It is possible still to create educative games that assist in the assimilation of new knowledge of trustworthy and constant form. The objective of this article is to raise the hypothesis of fetching constantly for products that motivate and satisfy the necessities increasing of the human being, conceives new products looking for to take care of the expectations of the satisfactory form. From this premise it is possible still to create educative games that assist in the assimilation of new knowledge of trust worthy and constant form from the satisfaction and motivation. However, the games have gained recognition as a half greater of what its original conception. The Games had entered in the context of the learning in areas as language, mathematics, science, computers, training, among others, with this development and ampler acceptance, the pure functions and right of games are gaining adoption expanded in applications non-game.
\end{abstract}

Keywords: Interaction Design, Game Design, User-centered Design, Game Elements

\section{Introdução}

O presente artigo trata sobre a importância do design de interação na criação de jogos educativo. Através de pesquisa bibliográfica exploratória demonstrase que esses profissionais atuam em diferentes frentes e são capazes de criar a possibilidade de se utilizar diversas ferramentas para facilitar a vida cotidiana.

O design está envolvido neste processo, quando os dados que são transformados em informações, passam a ser transformados em conhecimento para o cotidiano de aprendizagem, que está cada vez mais evidente com o desenvolvimento da tecnologia e na disseminação da informação, tornando fundamental a forma como os dados e informações são apresentadas e facilitando sua compreensão.

Operar nos cenários da época presente, deliberados como dinâmicos, fluidos, mutantes e complexos, tornouse um grande desafio para os designers, tentando apreender as áreas dos predicados intangíveis dos bens de consumo, fazendo dessa maneira, o design interagir sempre mais com outras áreas, compondo dessa maneira uma colaboração interdisciplinar (Moraes, 2010).
A principal competência do design sofre questionamentos nesse contexto, até então vista apenas com a característica de conceber bons produtos ou serviços. Pesquisadores buscam maneiras novas e viáveis para melhorar a contribuição do campo do design frente aos desafios de sustentação da sociedade contemporânea, "orientando esforços para sensibilizar, construir capacidades e implantar procedimentos práticos que contribuam para o desenvolvimento de economias sustentáveis por meio de ações, ferramentas e estratégias voltadas às mudanças profundas nos estilos de vida atuais" (Silva e Santos, 2009). Nessa nova realidade, os produtos passam a ser projetados mantendo o usuário como um dos mais relevantes focos.

\section{Problema}

Diante desta possibilidade o artigo parte da problemática de analisar princípios de design de interação na elaboração de jogos educativos, estabeleceuse a seguinte pergunta de pesquisa:

Como se aplica o design de interação no desenvolvimento para jogos educativos centrados no usuário?

\section{Objetivos Geral e Específicos}

Os objetivos desta linha de pesquisa é a realização de estudos 
sobre relação entre design, tendo por foco a educação e interação envolvendo um processo de aprendizagem.

Compreende a elementos de game em seus aspectos interativo e motivacional.

Apresentar os mecanismos de games adequados e aplicáveis no contextos educacional.

\section{Procedimentos Metodológicos}

Para a elaboração do presente estudo, optou-se pela realização de uma pesquisa com base em documentação indireta, a qual compreende basicamente o levantamento de dados de fontes variadas, em livros, revistas e mais documentos publicados sobre o tema. Objetiva-se recolher informações prévias sobre o tema do estudo, que foi a importância da pesquisa e extensão do design de interação para jogos educativos.

A coleta de dados da presente pesquisa se deu inicialmente através de revisão bibliográfica e documental em bases de dados como o portal periódicos CAPES, Scopus, ISI Web of Knowledge, Web of Science e Google Acadêmico.

Gil (2007) salienta que a pesquisa bibliográfica é efetuada a partir de material já elaborado. Essa técnica de pesquisa apresenta como principal vantagem o fato de possibilitar que o pesquisador tenha a cobertura de uma quantidade de fenômenos muito mais ampla do que aquela que poderia obter efetuando uma pesquisa de campo direta.

Para o desenvolvimento coerente de uma pesquisa científica, "a determinação dos procedimentos metodológicos a serem seguidos é fundamental" (Severino, 2000, p. 12). A postura investigativa adotada ao estabelecer uma atividade de pesquisa representa uma maneira de desenvolver a construção do conhecimento.

\section{Design de Interação}

Atualmente a tecnologias está disponibilizando produtos cada vez mais interativos, que estão sendo utilizados de maneira mais frequente em diversos contextos que acabam sendo incorporados ao uso cotidiano. O design de interação, nesse contexto, objetiva o redirecionamento dessa preocupação com a relevância focada no usuário final, trazendo a usabilidade para o seu processo e tratando especificamente do desenvolvimento projetual de produtos interativos, fáceis, agradáveis e úteis na perspectiva do seu usuário final.

O Design da Interação considera três aspectos: foco no usuário, definição de metas de usabilidade e iteração. $O$ foco no usuário é central no processo de design, de modo que o processo encoraja e provê oportunidades para a participação do usuário dentro do processo. Os critérios de usabilidade devem ser identificados, concordados e documentados no início do projeto e são importantes no momento da escolha das alternativas de design. Por último, iteração deve estar presente, pois, é por meio dela que se permite o refino baseado em resultados de avaliações de versões intermediárias (Gomes et al., 2008).
A preocupação primordial do design de interação é a criação de projetos interativos, com produtos que sejam de fácil aprendizagem, eficazes na sua utilização e capazes de proporcionar uma experiência gratificante a quem os usa.

Fileno (2011) apresenta ainda seu entendimento de design de interação que é assim expresso:

[...] o design de produtos interativos, como websites, PDAs, jogos eletrônicos e softwares, que fornecem suporte às atividades cotidianas das pessoas, seja no lar ou no trabalho, sendo fundamental para todos os campos e abordagens que se preocupam em pesquisar e projetar sistemas baseados em sistemas computacionais para pessoas. $O$ foco do Design de Interação são as relações humanas tecidas através dos artefatos interativos, que funcionam também como meios de comunicação interpessoal.

É importante acrescentar que o destaque de produtos interativos e usáveis demanda que sejam observados inicialmente o usuário que irá utilizá-lo e o local onde esse produto será empregado. O conceito de colaboração vem de muitos séculos, de diferentes áreas de conhecimento, adaptandose de, fundamentalmente, um trabalho conjunto entre pessoas com um objetivo comum, para a existência indispensável no processo de design atual, tido como fator influenciador no resultado final na concepção de um novo produto (Fontana et al., 2012).

Preece et al., (2007) argumentam que o design é uma atividade prática e criativa, que tem por objetivo final o desenvolvimento de produtos que auxilie os usuários a atingir suas metas. Por esse motivo, quando um novo produto é projetado, é preciso que se disponha de algum entendimento acerca do que se espera dele.

Para esses autores, o ato de projetar ou realizar designs envolve o desenvolvimento de um plano ou esquema. Para que eles possam ser executados, é preciso ter essencialmente o conhecimento sobre seu uso e público-alvo, e ainda, as restrições práticas quanto a material, custo e viabilidade. No design de interação, é investigado o uso de artefatos e o domínio-alvo a partir de uma abordagem de desenvolvimento centrada no usuário, o que significa que as preocupações a quem os usa direcionam o desenvolvimento mais do que as preocupações técnicas.

Bill Verplank (2007) define design de interação como design para pessoas. Para ele o design de interação precisa responder a três questões: (i) Como as pessoas agem? Através de affordances, propriedades percebidas e reais de um objeto, principalmente que fornecem indicações deoperação, maneira como as pessoas agem, manipulam e manuseiam apenas ao olhar; (ii) Como elas se sentem? Mostrar o efeito de uma ação, com os feedbacks. Muitas das emoções vem da qualidade sensoriais do meios comunicação com uma maquina ou sistema; e (iii) Como elas entendem? O que envolve o modelo mental de como saber o que fazer apresentando uma visão geral de como se dá o funcionamento de objetos ou sistemas.

A finalidade central do design é a sugestão de idéias que atendam aos requisitos de interação com o usuário. Produtos 
bem projetados compostos de elementos de linguagem visual estéticos podem aumentar a sua usabilidade, bem como o diminuir esforço cognitivo. Um ponto central nesse processo de design consiste em decidir inicialmente o que os usuários farão para conseguir realizar suas tarefas.

\section{Design Centrado no Usuário}

Para Santa-Rosa et al., (2012), a Experiência do Usuário (UX) está relacionada em como um indivíduo se sente enquanto usuário de um produto, sistema ou serviço e ao prazer e satisfação obtidos no contato com este artefato. Essa inclui aspectos subjetivos atribuídos a uma interação humanocomputador, mas de igual maneira, pode envolver a percepção de uma pessoa aos aspectos de usabilidade e facilidade para alcançar seus objetivos numa determinada interação. Sendo ainda considerada vital para todos os tipos de produtos e serviços e se não for provida de uma maneira positiva, as pessoas não os usarão mais. É preciso estar ciente, que não se projeta as experiências dos usuários, mas, criam-se as condições para que elas sejam invocadas.

No entendimento de Cabreira e Mülling (2012), os avanços tecnológicos possibilitam diferentes formas de interação, complexas e centradas no usuário.

Como destacado por Giraffa (2009) os ambientes, ferramentas e plataformas necessitam ser de fácil manuseio e devem permitir criar aplicações de aparência "profissional", do mesmo modo com os serviços, que precisam ser flexíveis.

Conforme entendimento de Preece et al., (2007), desenvolver produtos fáceis de aprender, eficazes e que proporcionam experiência agradável ao usuário faz parte do design de interação, que significa proporcionar ao usuário facilidades em seus trabalhos coloquiais, onde sua principal finalidade é o desenvolvimento de produtos utilizáveis que leva em consideração quem e onde o produto será utilizado, como também as atividades que serão executadas pelos usuários.

Importante destacar a importância da preocupação com o usuário no desenvolvimento de uma interface, essa só se mostra eficaz quando o usuário é capaz de realizar a ação por meio da ferramenta. A partir desse pensamento, surgiram processos de design que colocavam o usuário como figura central e partiam de suas características para definir o resultado final do artefato criado. Esse conjunto de métodos é englobado no conceito do design centrado no usuário, cuja principal característica está no envolvimento efetivo dos usuários finais no processo de design e na maneira como eles influenciam na forma do projeto (Fabrício et al, 2015).

O surgimento do termo "design centrado no usuário" é atribuído a Donald Norman, cuja pesquisa defende a usabilidade das interfaces afirmando a incoerência e os problemas decorrentes da dificuldade que existe no uso de objetos que fazem parte do cotidiano. O design centrado no usuário não é o mesmo que usabilidade, mas, ao projetar interfaces com foco no usuário, garante-se a usabilidade do sistema.

Norman (2002, p. 223) expõe os sete princípios da trans transformações de tarefas difíceis em tarefas simples:
1. Usar ao mesmo tempo o conhecimento no mundo e o conhecimento na cabeça.

2. Simplificar a estrutura das tarefas.

3. Tornar as coisas visíveis: assegurar que as lacunas de execução e avaliação sejam encurtadas ou superadas.

4. Fazer corretamente os mapeamentos.

5. Explorar o poder das coerções naturais e artificiais.

6. Projetar para o erro.

7. Quando tudo o mais falhar, padronizar.

A melhor maneira de criar um artefato ou um sistema de que as pessoas necessitam, é através do envolvimento dos usuários finais no processo de desenvolvimento desses produtos. Nesse sentido, o design centrado no usuário se contrapõe a processos menos focados no ser humano, que costumam prever seu comportamento. Para que os usuários sejam abarcados por esse desenvolvimento, as etapas metodológicas do design centrado no usuário compreendem a construção de protótipos avaliáveis, que produzirão material sólido para que o produto seja favorável, agradável, usável e suficiente. Esse material terá condições de ser coletado pelo julgamento crítico da interação com esses protótipos, entrevistas e questionários.

Esses autores acrescentam que o protótipo é uma representação limitada de um game design que permite aos usuários interagir com ele e explorar a sua conveniência. Protótipos respondem a diversas questões e fornecem suporte aos game designers para a escolha de uma dentre as diferentes opções. Servem para fins variados, tais como: testar a viabilidade técnica de uma ideia; esclarecer alguns requisitos vagos aos desenvolvedores; realizar testes com usuários e avaliações; verificar se os rumos tomados pelo design são compatíveis com os objetivos do projeto.

\section{Game Design}

Fabrício et al (2015), destacam que game design não está no código, arte ou som. Não está em esculpir as peças de um jogo ou ilustrar um jogo de tabuleiro, significa elaborar as regras que dão vida a todas essas peças.

Isto é, game design significa fazer uso de todos os recursos que o profissional puder reunir para criar uma experiência envolvente que motiva os comportamentos desejados. Algumas das melhores coisas que os jogos fazem, são encorajar o jogador a resolver problemas, manter o interesse de iniciante até expert e de expert até mestre, quebrar grandes desafios em etapas administráveis, promovendo o trabalho em equipe, oferecer aos jogadores uma sensação de controle, personalizar a experiência para cada participante, reduzir o medo do fracasso que inibe a experimentação inovadora, suportar diferentes interesses e habilidades, além de cultivar uma atitude confiante e otimista.

A interatividade é um componente importante do design de produtos tecnológicos destinados à mediação com seres humanos. Levando-se em conta a interatividade como qualidade do produto e a interação a relação que ocorre entre o usuário e o ambiente, a utilização de mecânicas e 
técnicas adotadas no Design de Games tem por escopo tornar os ambientes mais interativos e estreitar as relações entre usuário e sistema.

De acordo com Feijó (2015, p. 107):

Como alternativa de ampliação de possibilidades criativas, a partir de uma especificação dos arquétipos, a metodologia de design considera que determinados grupos ou neo-tribos desenvolvem contextos comuns de consumo e gosto, portanto, ao projetar um conteúdo o primeiro passo é detalhar características padronizadas no público-alvo, utilizando-se até de estereótipos desse determinado grupo, e esbanjar de conexões e relações entre essas características e a temática/função da narrativa.

Teixeira (2010), por sua vez, destaca que os fatores que inspiram a conduta do consumidor neste contexto, são: mercadológicos, culturais, sociais, pessoas e psicológicos. Essas considerações devem fazer parte da compreensão embrionária do designer de conteúdo, já que, seu objetivo principal é o usuário/consumidor.

Para Santaella (2009, p. 64-65), a compreensão dos usuários/consumidores é auxiliada pelas narrações que existem no mercado, qualquer que seja a área a ser abordada. Uma vez que: "A conversação dos games com outras mídias, especialmente com filmes, é abusivamente frequente. Muitos designers de games extraem elementos de histórias de filmes existentes ou de gêneros literários (...). Traduções semióticas de peças literárias também são frequentes". Essa afinidade é distinguida como auto-referencialidade, onde a mídia progrediu para um multiverso adequado que consente o emprego de elementos figurativos ou abstratos de diversas narrativas, que já tenham seu próprio universo expandido, impetrando uma conexão imersiva com um assentado público que já funcionou e propende a resultar de maneira positiva.

Acrescente-se ainda que, de acordo com Menezes (2015), a gamificação busca desenvolver a interação do usuário, em contextos variados, através da utilização de elementos de games. Não se trata da adoção de jogos completos, mas, de algumas das características destes com a finalidade de acrescentar motivação à utilização do ambiente.

O projeto de interfaces gráficas interativas, através da crescente utilização da Internet, tornou-se um desafio para os gamers, diante da infinidade de ferramentas e recursos disponíveis para o designer, principalmente quando se pretende construí-las para que sejam fáceis de usar, simples, diretas, agradáveis e divertidas, proporcionando aos seus usuários uma maior concentração na tarefa a ser desempenhada.

Isto leva a perspectivar o game designer como alguém que, antes de tudo, consegue antecipar o perfil psicológico do jogador e a satisfação emocional que este poderá extrair do jogo. Ou seja, alguém que parte de uma visão artística e sensível do jogo que procura transpor para uma experiência emocional dentro de um conjunto de parâmetros tecnológicos e técnicos e de determinadas condições sociais e profissionais (Palinhos, 2012).
Com esse entendimento, cabe ao Game Designer apresentar um intrínseco conhecimento da natureza humana, suficiente criatividade que consinta a geração de objetos que inquiram essa natureza, conhecimentos técnicos que lhe admitam pôr essa criatividade em exercício contínuo e a capacidade de liderança que admitam dirigir o pessoal técnico responsável pela produção do jogo.

\section{Jogos Educativos}

Procurando por formas adequadas e interessantes para o ensino a educação tem utilizado constantemente as tecnologias digitais, sendo que os jogos é tida como uma das modalidades mais procuradas, pois, têm se mostrado eficazes ferramentas de ensino, nomeadamente para crianças, tornando o aprendizado mais divertido, possibilitando que o conteúdo transmitido seja fixado mais facilmente. Sendo a interface a base para interação entre o homem e a máquina, é importante que o jogo tenha uma interface intuitiva, usual, clara, consistente e atrativa para obter a aceitação dos usuários.

Os jogos eletrônicos, sejam educativos ou não, envolvem um grande processo de aprendizagem. Seus desafios crescentes, sua variedade de desafios e o dinamismo deste mercado, lançando cada vez mais jogos com grande velocidade, garantem que no mínimo, o jogo tenha que ser aprendido ao ser jogado pela primeira vez (Albuquerque e Fialho, 2009).

A narrativa nos jogos eletrônicos, mesmo que minimamente, sempre dependeu da interação do jogador com o mundo virtual, esse elevado grau de imersão tende a tornar toda a experiência mais atrativa, quando permite uma relação mais direta entre as ações de entrada de comandos do jogador e as ações realizadas pelo avatar, além de ser mais acessível, o que acaba por agradar uma parcela maior do público, resultando em maior número de jogadores casuais (Aguiar et al., 2009).

Com o aparecimento de novas necessidades para a conservação da vida e a sofisticação do trabalho, os jogos passam a fazer parte de diversos contextos, atendendo a necessidade de civilizações distintas (McGonigal, 2012). Qualquer que seja a origem, jogos, em suas mais diferentes manifestações, encontram-se na história da humanidade desde seus primórdios.

Conforme entendimento de Huizinga (2012), o jogo é uma função da vida, não sendo passível de definição exata - quer seja em termos lógicos, ou em termos biológicos e estéticos. Destaque-se, que seu conceito deve diferenciar-se das demais maneiras de atividades e de construções do pensamento com as quais os seres humanos manifestam a estrutura de suas vidas social e espiritual. É provável que se possa apresentar suas principais características, sejam elas próprias de jogos em geral e outras encontradas apenas em jogos sociais.

$\mathrm{Na}$ atual conjuntura cultural o jogo digital encontra vasto espaço. Qualquer que seja a cultura encontra apoio no lúdico para se repetir, já que as finalidades fundamentais da cultura em sociedade é potencializar as relações sociais entre os indivíduos 
e transmitir conhecimentos (Bueno e Bizzelli, 2014).

Assim, os jogos digitais devem ser entendidos como sistemas de simulações, onde situações reais são substituídas por situações lúdicas, que permitem que os jogadores vislumbrem modelos diferentes de realidade. Ocupam, portanto, espaço importante na socialização dos indivíduos e na formação de sua personalidade. A criação experimental lúdica promove um novo modo de se produzir e difundir o conhecimento, o qual tem seu lugar na sala de aula. (Bueno e Bizzelli, 2014, P. 166-7).

A inserção das tecnologias nas práticas educativas se mostra primordial, o que leva a consideração do real potencial das inovações para a educação e a forma de inseri-las nos ambientes educativos, tarefa que pressupõe uma quebra de paradigmas e uma busca pela construção de práticas que reputem de maneira positiva reconstruções do currículo escolar vigorante. É preciso ainda que a comunidade escolar se aproprie da linguagem peculiar à tecnologia digital.

Os jogos digitais devem ser vistos como ferramentas sofisticadas para serem utilizadas na educação, já que exigem diversos tipos de pressupostos e conhecimentos prévios que tornam o aprendizado uma tarefa complexa. Destaque-se, que os jogos bons mantêm o interesse dos jogadores, ainda que existam dificuldades, o que faz com que aprendam seu funcionamento e lógica, permitindo êxito nas ações realizadas. Os jogos facilitam a aprendizagem, pois criam motivação para o comprometimento com o que está sendo realizado, apresenta noção de preparação para o aprendizado futuro, despertando os conhecimentos prévios e provocam a tomada de decisão por parte dos jogadores (Bueno e Bizzelli, 2014).

O diferencial do trabalho com os jogos digitais em contexto educativo é a maneira como eles são utilizados e a compatibilidade entre o conteúdo apresentado e o aprendiz, já que se esses itens não forem levados em consideração, a aprendizagem não ocorrerá, como acontece com qualquer outra metodologia. Os alunos atuais representam as primeiras gerações que cresceram com as novas tecnologias. Desde seu nascimento, foram cercados e sempre utilizaram computadores, videogames, câmeras, telefones celulares e outros brinquedos e ferramentas da era digital.

Para Albuquerque e Fialho (2009) o esforço cognitivo aplicado aos problemas complexos dos jogos - entre outros fatores - promove o denominado Sleeper Curve: ao contrário do que se imaginava, a relação precoce com as mídias de massa torna seus usuários cada vez mais inteligentes e exigentes.

Clua (2007) enfatiza que a motivação é um fator importante no ensino, uma vez que o aprendizado pode ser facilitado quando se utiliza ambiente e conceitos de jogos por possuírem grande apelo visual e interativo comparado as formas de ensino tradicionais.

Senna (2007) argumenta que a alteração nas artes audiovisuais e educação causada pelos jogos, é responsável por despertar o interesse das pessoas e fazer com que se torne ponto importante para a cultura brasileira. Os jogos educacionais levam conteúdo pedagógico a um novo universo, onde crianças fazem uso do computador cada vez mais frequentemente. Professores norte americanos, argumentam que os jogos é uma boa maneira de prender a atenção dos alunos e fazer com que entendam o conteúdo, pois causam impactos e despertam a curiosidade.

Albuquerque e Fialho (2009) acrescentam que a interatividade dos jogos eletrônicos exige um comportamento ativo do jogador. O desafio do jogo exige um investimento de energia mental que posiciona o jogador em um nível mais elevado de interação: o aprendizado sobre algo que ele influencia ativamente possibilita que perceba, não somente o contexto por outro ponto de vista, mas, de igual forma, que amplie a habilidade de resolver outros problemas relacionados ao conteúdo em questão.

\section{Elementos de Jogos}

Em termos de aprendizagem, os games são ótimas ferramentas que diminuem o tempo necessário para o aprendizado de um conceito, já que, quando focados na essência são diminuídas as resistências provenientes da realidade.

Os elementos de games são a caixa utilizada pelos usuários para criar a solução de aprendizagem gamificada. Esses podem ser conceituados, de acordo com Werbach (apud Alves, 2014, p. 56): "Elementos são padrões regulares que podem ser combinados de diferentes maneira para que você construa um jogo".

Quando se foca em aprendizagem, o gamification está em busca da produção de experiências engajadoras e que mantenha os jogadores focados em sua essência para aprendam algo impactante para sua vida (Alves, 2014).

Essa autora destaca que o game pode ser pensado de duas formas distintas, na primeira serve como um instrumento usado para a promoção de uma experiência, a segunda proporciona o "pensamento de jogos", uma vez que promove a busca da melhor combinação de elementos e como correlaciona-los para produzir uma experiência adequada a aprendizagem se efetue.

A envolvência visual, sonora e a narrativa são aspectos primordiais, para a atratividade do jogo, constituindo, na maioria das vezes, a sua primeira finalidade. No entanto, se for entendido o jogo eletrônico como uma experiência estruturada e interativa sustentada por tecnologia informática, torna-se manifesto que os seus elementos fundamentais são:

1. a existência de uma estrutura formal de regras e mecânicas que sustente as ações dos jogadores;

2. a existência de uma forma de comunicação entre o ser humano e o dispositivo digital;

3. a programação das instruções necessárias para que o sistema informático possa descodificar as ações humanas e reagir a elas de forma apropriada (Palinhos, 2012).

A estética empregada no game é responsável pela criação de alguma forma do senso de verdade para esta experiência e gera a credibilidade necessária para que a experiência aconteça de forma desejada (Alves, 2014).

O estudo do Gamification se apoia no tripé: mecânica, 
dinâmica e estética, e, a relação entre eles é essencial para o sucesso de um projeto com a utilização de Gamification. A dinâmica é constituída por elementos responsáveis pela atribuição de coerência e padrões regulares à experiência. Entre esses elementos, podem-se citar: constrições, emoções, narrativa, progressão e relacionamento (Alves, 2014).

Sobre a mecânica dos games, essa mesma autora acrescenta que os elementos podem ser considerados como verbos, uma vez que são os promotores da ação, dentre esses destaque-se: os desafios, a sorte, a cooperação e competição, o feedback, a aquisição de recursos, as recompensas, as transações, os turnos e os estados de vitória.

Sobre os componentes, que são formas específicas de fazer a representação da dinâmica e mecânica, esses são considerados substantivos, tais como: realizações, avatares, badges, "boog fights", coleções, combate, desbloqueio de conteúdos, doar, placar ou "leaderbord, níveis, pontos, investigação ou exploração, gráfico social, bens virtuais.

Para Alves (2014, p. 64): "Experiência e game não são a mesma coisa". Uma vez que, experiência é a maneira como o jogador se sente quando joga e game é o conjunto de regras, estética, combinação entre seus elementos que provoca essa experiência.

No momento de se elaborar o design de um game, se está controlando o game e tentando que experiências sejam produzidas. Entende-se assim, que os elementos são as peças combinadas para promover determinada experiência.

\section{Resultados e discuções}

Para o design, quanto mais alternativas forem encontradas, maior será o repertório. Ampliam-se assim as opções de soluções para velhos e novos problemas. Quando um paradigma é revisto, depara-se com uma nova forma de pensar que vem sempre acompanhada de uma evolução no campo do saber, atentando-se a característica versátil do próprio design.

Além disso, o propósito dos jogos educativos é a interação do jogador com o conteúdo de uma forma dinâmica, envolvente, multimídia e interativa. Determinados jogos podem ir além, explorando estratégias de aprendizagem e resolução de problemas complexos, além de familiarizar o estudante com a tecnologia.

O processo proposto valoriza o jogador como um tomador de decisões, e tenta conceber jogos que possam relacionar conteúdo e funcionamento do jogo. Neste processo 1 primeiro passo é conhecer o conteúdo que deve ser trabalhado pelo jogo eletrônico. Este passo vai exigir algum estudo e preparação do designer de jogos, ou a participação de um especialista na equipe (Albuquerque e Fialho, 2009, p. 4).

As etapas de concepção de um jogo são: conteúdo; encontrar dilemas; seleção de dilemas; transformar dilema em desafios; gênero; aspectos do jogo; aspectos do conteúdo; e, elaboração do documento de game design.

De uma maneira geral, a questão dos jogos eletrônicos educativos não se resume a uma questão de produção, mas também - e talvez, principalmente, de utilização, que ainda exige trabalho e pesquisa. A situação onde o jogo será utilizado irá revelar outras demandas: no caso das escolas, há a necessidade dos professores, que precisam de incentivo, equipamento, formação e apoio para que possam planejar e executar atividades; no caso de crianças os pais podem incentivar a indústria a produzir e os filhos a jogar, adquirindo o jogo, jogando com eles, aceitando envolver-se nessa cultura de simulação mesmo que não se sintam em um local seguro (Moita 2006).

O Design de Interação, para a jogos educativos é composto por quatro atividades básicas: (i)Identificação das necessidades dos usuários, (ii) desenvolvimento de alternativas de design, (iii) construção de versões iterativas e (iiii) avaliação do design. É importante destacar que essas atividades estão interrelacionadas fornecendo informações umas às outras, e, também podendo ser repetidas.

Através destes levantamentos apresentados nesta seção e nos tópicos anteriores pelos autores referenciados nesta pesquisa, identifica-se que os principais processos de design de interação necessários para a o desenvolvimento de jogos educativos são: (i) identificar as necessidade do usuário, (ii) compreender o cenário, o contexto que será utilizado, como o usuário interage através de que meios, (estética e usabilidade), (iii) apresentação visual, coerência e clareza nos elementos visuais, disposição dos conteúdos, utilizar metáforas e navegação estruturada proporcionando ao usuário a construção do modelo mental das funcionalidades (estética, usabilidade e cognição).

A experiência didática associado ao design soma as áreas (design, pedagogia) facilitando a busca do saber, ampliando o raciocínio, contribuindo no desenvolvimento do potencial intuitivo, lógico e criativo do aluno. A imagem possui uma função informacional e em geral, traz os conteúdos com tamanha rapidez que se relaciona com o usuário de forma diferenciada e que um jogo bem planejado em um primeiro momento exerce atração através da identificação e posteriormente pelo desafio e possibilidades que instiga.

\section{Conclusão}

É preciso observar o meio além de outras formas, além da auditiva e visual, comumente observadas. Isso, porque o espaço deve ser analisado de forma mais sensível, mais tátil, distante do privilégio apenas visual. Pois, pode-se experienciar, de forma não apenas retiniana, além do espaço, a própria alteração produzida. A possibilidade de um olhar crítico sobre um fenômeno depende da construção desse olhar a partir das experiências, que passam a ser mediadas por dispositivos tecnológicos.

Os dispositivos tecnológicos atuais apresentam inovações e possibilidades que despertam o interesse em projetar cada vez mais soluções complexas, criando uma verdadeira competição para a criação de interfaces que se beneficiem 
desses recursos.

O design de interação é a área do design que lida com o incentivo e com o impedimento de obstáculos entre as interações/comunicações entre seres humanos e determinados produtos ou serviços. Para isso, faz-se necessário investir muito tempo em pesquisas, análises de relatórios e, notadamente em interação, já que o design de interação não trata somente de computadores e outros equipamentos, mas de forma especial, de seres humanos, que são os usuários dos sistemas analisados, e devem estar inseridos no decorrer dos projetos de criação e correção de um produto, acabando por tornarem-se mais do que ajudantes.

Entre tanto espera-se contribuir para a aplicação do design interação no desenvolvimento para jogos educativos na aprendizagem a fim de elencar os processos de design de interação mais relevantes como o (i) foco no usuário, (ii) a estética, (iii) usabilidade e (iii) cognição para que se aplique em jogos centrados no usuário.

\section{Agradecimentos}

Agradecemos ao Comitê Executivo Internacional da SIGraDi 2015. Programa de Pós-graduação em Design, Coordenação de Aperfeiçoamento de Pessoal de Nível Superior (Capes) e Universidade Federal de Santa Catarina (UFSC).

\section{Refêrencias}

AGUIAR, Bernardo; SOARES, Nilson; CAMPOS, Fábio. Possibilidades de interface e imersão em novas tecnologias no design de jogos. III Simpósio Nacional ABCiber - Dias 16, 17 e 18 de Novembro de 2009 - ESPM/SP - Campus Prof. Francisco Gracioso.

ALBUQUERQUE, Rafael e FIALHO, Francisco. Concepção de jogos educativos: Proposta de processo baseado em dilemas. In: VIII Simpósio Brasileiro de Jogos e Entretenimento Digital, 2009. Anais... Rio de Janeiro: Sociedade Brasileira de Computação, 2009.

ALVES, Flora. Gamification: como criar experiências de aprendizado engajadoras. Um guia completo: do conceito à prática. São Paulo: DVS Editora, 2014.

BUENO Clerison José de Souza; BIZELLI Luís José. A gamificação do processo educativo. Revista Geminis - ano 5 n. 2, 2014 - p. 160-176.

CABREIRA, Arthur; MÜLlING, Tobias. Perspectivas para novas interfaces: Kinect e interações gestuais sob o panorama de interfaces naturais do usuário. $4^{\circ}$ Congresso Sul Americano de Design de Interação 2012.

CLUA, Esteban G. Diversão que Ensina. Computação Brasil, Revista da Sociedade Brasileira de Computação, Jun/Jul/Ago, 2007.

FABRÍCIO, Marcos André; BONETTI, Matheus Henrique; GRASSI, Nicholas Bruggner; VALENTE, Vânia Cristina Pires Nogueira; FERASOLI FILHO, Humberto. Tutoriais gamificados e o design centrado no usuário. Revista Geminis - ano 6 - n. 1
- p. 62-78. 2015.

FEIJÓ,Marcos Vinícius. Design de conteúdo como metodologia para produção de narrativa fantástica. Revista Geminis - ano 6 - n. 1 - p. 101-124. 2015.

FILENO, Érico. Design de interação. (2015, Julho 20) Disponível em: http://ericofileno.wordpress.com/tag/interacao/.

FONTANA, Isabela Mantovani; HEEMANN, Adriano; FERREIRA, Marcelo Gitirana Gomes. Design Colaborativo: Fatores Críticos para o Sucesso do Co-design. $4^{\circ}$ Congresso Sul Americano de Design de Interação. São Paulo, 2012.

GIL, Antonio Carlos. Como elaborar projetos de pesquisa. 4. ed. Sio Paulo: Atlas, 2007.

GIRAFFA, Lucia Maria Martins. Uma odisséia no ciberespaço: O software educacional dos tutoriais aos mundos virtuais, Revista Brasileira de Informática na Educação, v. 17, n. 1, 2009. GOMES, Alex Sandro; MELO, Cássio; ARCOVERDE, Daniel; MONTEIRO, Bruno; ALVES, Carina Frota. Design da Interação de Novos Produtos para TVD: Abordagens Qualitativas, in VIII Simpósio Brasileiro de Fatores Humanos em Sistemas Computacionais (IHC 2008), Full paper, Porto Alegre, Brasil, 2008.

HUIZINGA, J. Homo Ludens: o jogo como elemento da cultura. 7. ed. São Paulo: Perspectiva, 2012.

MCGONIGAL, J. A realidade em jogo: porque os games nos tornam melhores e como eles podem mudar o mundo, Rio de Janeiro: BestSeller, 2012.

MOITA, Filomena M. G. DA S. Cordeiro. 2006. Games: Contexto Cultural e Curricular Juvenil. 2006. 181 f. Dissertação (Doutorado em Educação). Universidade Federal da Paraíba. MORAES, Dijon de. Metaprojeto: o design do design. São Paulo: Blucher, 2010.

NORMAN, Donald A. O design do dia-a-dia. Rocco. 2006.

FEIJÓ, Marcos Vinícius. Design de conteúdocomo metodologia para produção de narrativa fantástica. Revista Geminis - ano 6 - n. 1 - p. 101-124. 2015.

MENEZES, Graciela Sardo. Gamificação no contexto da experiência do usuário: estudo dos elementos de game na satisfação de desejos e necessidades subjetivas dos indivíduos. Dissertação de Mestrado. Universidade Federal de Santa Catarina, 2015.

PALINHOS, Jorge. Breve Introdução ao Game Design. Teoria dos Jogos -Design de Jogos Digitais -2012/13.

PREECE, Jennifer; ROGERS, Yvonne; SHARP, Helen. Design de Interação: Além da interação homem-computador. Porto Alegre: Bookman, 2007.

SANTAELLA, Lucia. Mapa do jogo: a diversidade cultural dos games. São Paulo: Cengage, 2009.

SANTA-ROSA, José Guilherme; REBOUÇAS, Andrei Gurgel de Araújo; PASSOS, Marcel. Experiência do Usuário e Design de Interfaces no Contexto Universitário. $4^{\circ}$ Congresso Sul Americano de Design de Interação 2012.

SEVERINO, Antonio Joaquim. Metodologia do Trabalho Científico. 21. ed. rev. e ampl. São Paulo: Cortez, 2000.

SENNA, Orlando. Diversão que Ensina. Computação Brasil, Revista da Sociedade Brasileira de Computação, Jun/Jul/Ago, 
2007.

SILVA, Jucelia S. Giacomini; SANTOS, Aguinaldo dos. O conceito de sistemas produto-serviço: um estudo introdutório. III Encontro de Sustentabilidade em Projeto do Vale do Itajaí, 2009.
TEIXEIRA, José Carlos Inocente. Fatores que influenciam o comportamento do consumidor. Rio de Janeiro: Universidade Cândido Mendes, 2010.

VERPLANK Bill, MOGGRIDGE, Bill. Designing Interactions. The MIT Press (2007). 